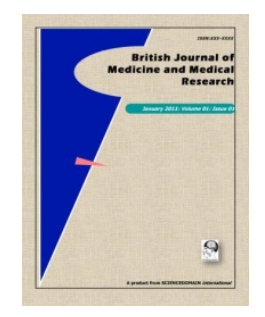

British Journal of Medicine \& Medical Research 3(3): 710-721, 2013

SCIENCEDOMAIN international

www.sciencedomain.org

\title{
Spondylolisthesis in a City in South South Geo-Political Zone of Nigeria
}

\author{
U. Uduma Felix ${ }^{1 *}$, N. Dim Edwin ${ }^{2}$, E. Nottidge Tim ${ }^{2}$ \\ and U. Eduwem Dianabasi ${ }^{1}$ \\ ${ }^{1}$ Department of Radiology, College of Health Sciences, University of Uyo, Nigeria. \\ ${ }^{2}$ Department of Trauma and Orthopaedics, College of Health Sciences, University of Uyo, \\ Nigeria. \\ Authors' contributions \\ This work was done in collaboration with all authors. Author UUF conceived and designed \\ the study. Authors UUF and NDE wrote the protocol and the first draft of the manuscript. \\ Authors UUF, NDE, ENT and UED managed the analysis, literature searches and \\ Tables/Figs. All authors revised and approved the revised manuscript.
}

Research Article

Received $21^{\text {st }}$ July 2012 Accepted $5^{\text {th }}$ November 2012 Published $28^{\text {th }}$ February 2013

\section{ABSTRACT}

Background: Spondylolisthesis is a condition where one vertebra slips over the top of the adjacent vertebra. This is commonest in the lumbar spine.

Objectives: To audit lumbo-sacral spine radiographs for spondylolisthesis with emphasis on localisations, sex distribution, types and grading.

Materials and Methods: A descriptive cross sectional study was carried out from $1^{\text {st }}$ May, 2011 to $21^{\text {st }}$ June, 2012 in Radiology Department, University of Uyo teaching hospital, Uyo, Nigeria. Recruited patients were referrals for lumbo-sacral radiography irrespective of indications. Anterior-posterior and lateral radiographs of the lumbo-sacral spine were taken under standardized conditions. Radiographs with spondylolisthesis were identified and analysed statistically using computer SSPS 13.

Results: 249 Patients were studied (132 Males and 117 females). 9.24\% ( $n=23)$ of the studied population had 25 individual vertebral displacements. $82.61 \%(n=19)$ of these patients were females and $17.39 \%(n=4)$ were males (female to male ratio $-4.75: 1)$. The mean age for males with vertebral displacement was $44.5(\mathrm{~S} . \mathrm{D}=10)$ while the mean age for females was 44.5 (S.D=15.81). The commonest level of vertebral involvement was L4 on L5. This was seen in $56.52 \% \quad(n=13)$ of patients with positive cases of 
spondylolisthesis. This was followed by L5 on S1 with $30.43 \% .82 .61 \%$ of patients had grade 1 displacements. Degenerative spondylolisthesis was the commonest type $(52.17 \%)$, followed by isthmic type $(21.74 \%)$, uncategorised $(17.39 \%)$ and traumatic spondylolisthesis $(8.70 \%)$.

Conclusion: Radiographic pattern of spondylolisthesis in Uyo, Nigeria demonstrates the usual female gender bias, L4/L5 localizations but interestingly show predominance in degenerative spondylolisthesis.

Keywords: Spondylolisthesis; lumbo-sacral radiographs; degenerative.

\section{INTRODUCTION}

Spondylolisthesis is anterior or posterior slippage of a vertebra or the vertebral column in relation to the vertebrae below. Such forward slippage is referred to as anterolisthesis, while backward slippage is retrolisthesis [1].

Spondylolisthesis was first described in 1782 by Dr Herbinaux, a Belgian obstetrician. He reported in a small number of patients, a bony prominence anterior to the sacrum that obstructed the vagina $[2,3]$. The term "spondylolisthesis" was coined in 1854, from the Greek words spondylo, meaning spine, and listhesis, meaning to slip or slide [3].

Aetiologically, there are five major types of lumbar spondylolisthesis. Based on Wiltse classification system, there are dysplastic, isthmic, degenerative, traumatic, and pathologic spondylolisthesis $[1,3,4,5]$. Dysplastic or congenital spondylolisthesis is caused by a defect in the formation of the facet of a vertebra that allows it to slip forward [1,4]. Hereditary lesions like malformation of the lumbo-sacral junction, small incompetent facet joints, upper sacrum abnormality, dysplasia of L5 neural arch and spina bifida may be seen $[2,3,6]$.

Isthmic or spondylolytic spondylolisthesis (ISS) is due to a defect (spondylolysis) in a portion of the vertebra called the pars interarticularis [7]. Pars interarticularis is defined as the parts of the neural arch that lies between the superior and inferior articular facets $[1,6]$. It is also roughly the region of the junction of the pedicle and lamina. ISS can be caused by repetitive trauma and this is more common among athletes [1,4,8,]. Toueg, et al. [8] observed in their study that $75 \%$ of spondylolysis cases develop into spondylolisthesis. The spectrum of disease in ISS range from bone stress (earliest sign) through spondylolysis (a non-displaced fracture of the pars interarticularis) and spondylolisthesis $[9,10]$. Anatomically defined factors, such as sagitally oriented facet joints, increased pedicle-facet angle, and horizontalisation of the lamina, are non-modifiable aetiologic factors of spondylolisthesis $[2,11]$.

Degenerative spondylolisthesis (DS) occurs due to cartilage degeneration and arthritic changes in vertebral joints [1,4]. It is more common in older patients with slippage occurring in an intact neural arch [4].

Traumatic spondylolisthesis is due to direct trauma or injury to the vertebrae. This can be caused by a fracture of the pedicle, lamina or facet joints that allows the anterior portion of the vertebra to slip forward with respect to the posterior portion of the vertebra [1,4].

Pathologic spondylolisthesis is slippage caused by a bone defect resulting from neoplasm (giant cell tumour), infections (tuberculosis), metabolic diseases, Paget disease and 
iatrogenic $[1,3,4,12.13,14]$. Gross destruction of anterior elements due to tuberculosis may place excessive stress on the posterior elements thereby precipitating spondylolisthesis [14].

Spondylolisthesis is equally graded and this is based on severity of slip. The most commonly used is Meyerding grading system [3,7]. This is based on the ratio of amount of slippage to vertebral-body width obtained as a percentage $[1,3,15]$. This is best achieved with lateral lumbo-sacral radiographs. Here measurements of the distance from the posterior edge of the superior vertebral body to the posterior edge of the adjacent inferior vertebral body is made. This distance is then reported as a percentage of the total superior vertebral body length [1,3]. Grade 1 is a ratio of $0-25 \%$, grade 2 is $25-50 \%$, grade 3 is $50-75 \%$, and grade 4 is $75-100 \%[1,12,16]$. When slippage is over $100 \%$, it is called Spondyloptosis. In this condition, the vertebra completely falls off the supporting vertebra $[3,12,16]$. This was later added as grade $\mathrm{V}$ describing the ptosis of the cranial vertebra [7].

Another grading system simply categorises spondylolisthesis as either low or high grade. Low grade spondylolisthesis is a slip that is less than $50 \%$ whereas greater than $50 \%$ is high grade [3].

Spondylolisthesis is commonest in the lumbar spine [1,3]. This is specifically most often seen at L4/L5 level $[3,15]$. Spondylolisthesis is one of the diagnoses conventional radiography is unambiguous about. In this regard, lateral view can be used both for grading and classification. Lateral view is specifically useful in detecting spondylolisthesis as it may demonstrate the pars defect $[1,7]$. This in combination with other views can hazard instigating pathology. In addition, ancillary conditions related to spondylolisthesis like vertebral formation anomalies, spondylosis, osteoid osteoma, Paget disease, fractures and osteolytic lesions are readily detectable with conventional radiography [1].

To explore spondylolisthesis in a Nigerian population should be considered meaningful since when symptomatic can increase work absenteeism. Hence, taking a toll on economic resource of a developing nation. Our objective is therefore to audit lumbo-sacral spine radiographs for spondylolisthesis with emphasis on localisations, sex distribution, types and grading.

\section{MATERIALS AND METHODS}

Consecutive Patients who came for lumbo-sacral radiographs on any account were prospectively studied from $1^{\text {st }}$ May, 2011 to 21 st June, 2012. These patients were referred to Radiology Department, University of Uyo Teaching Hospital, Uyo, Akwa Ibom State, Nigeria both from within and outside the hospital. Their clinical and demographic data were extracted, Patients' consents were sought prior to radiographic examinations. Lumbo-sacral spine radiograph for each patient was taken according to standard protocol with centring point at L2.

In anterior-posterior view, patient lay supine in the centre of an x-ray couch with arms and hands to the side of the body. The knees were raised with the soles of the feet resting on the couch top to reduce lumbar curve to minimum. The trunk was ensured to be straight with the pelvis not rotated. Patient's shoulders and raised legs were supported on pillows to immobilize the patient. Anatomical marker was placed, beam collimated and gonad shield applied. Centring point was midline at L2. The direction of central ray was directed 90 degrees vertically to the centre of the film. Focal film distance was $90 \mathrm{~cm}$ and exposure was made at arrested respiration in a $30 \times 40 \mathrm{~cm}$ detail or fast screen cassette. 
In lateral view, patient lay in left lateral position but with the arms raised to the head and the head supported on a pillow. The hips and knees were flexed with the legs placed in comfortable positions using sandbags. Centring point was $10 \mathrm{~cm}$ anterior to the spinous process of L2. Direction of central ray was also vertical at 90 degrees to the film. Paired radiographs of anterior-posterior and lateral per patient were used for evaluation of any vertebral displacements and associated pathology. Lateral radiographs were specifically used for grading of spondylolisthesis using Meyerding grading system. Exclusion criteria included non-optimal and non-standardized radiographs as well as patients without complete bio-data. Results were analysed using SPSS 13.0 for Windows software package (SPSS, Chicago, III).

\section{RESULTS}

249 Patients were studied with 132 Males and 117 females giving a male to female ratio of $1.13: 1$. The youngest age range was second decade of life. Studied population in both sexes increased progressively down the ages, peaking at $5^{\text {th }}$ decade of life. This subsequently and progressively decreased to $8^{\text {th }}$ decade of life. At the peak population, males were 30 $(22.73 \%)$ in number and females were $38(32.48 \%)$. Twenty-three patients constituting $9.24 \%$ of the studied population had vertebral displacements. Of this number, 19 patients $(82.61 \%)$ were females and 4 patients (17.39\%) were males giving a female to male ratio of $4.75: 1$ (See Table 1). The mean age for males with vertebral displacement was $44.5(S . D=10)$ and mean age for female was 44.5 (S.D =15.81). 25 individual vertebral displacements were seen in these 23 patients. In females, the modal age for vertebral displacement was 54.5 while it is 44.5 for males.

Table 1. Sex distribution of spondylolisthesis

\begin{tabular}{lll}
\hline Age Range & Male & Females \\
\hline $0-9$ & 0 & 0 \\
$10-19$ & 0 & 0 \\
$20-29$ & 0 & 1 \\
$30-39$ & 1 & 4 \\
$40-49$ & 2 & 3 \\
$50-59$ & 1 & 7 \\
$60-69$ & 0 & 4 \\
$70-79$ & 0 & 0 \\
$80-89$ & 0 & 0 \\
$90-99$ & 0 & 0 \\
TOTAL & 4 & 19 \\
\hline
\end{tabular}

The commonest level of vertebral involvement was $L 4$ on $L 5$, seen in 13 patients constituting $56.52 \%$ of positive cases of spondylolisthesis (See Table 2). This was followed by 7 patients $(30.43 \%)$ at vertebral L5 on S1. L1 displacement on L2 and L3 on L4 were seen in 2 patients $(8.70 \%)$ each. Grade 1 spondylolisthesis was the commonest grade (See Fig. 2). Twentyone $(91.30 \%)$ patients had Grade 1 displacements with female to male ratio of $6: 1$. Grade 2 was $4.35 \%(n=1)$, grade $3-0 \%$ and grade 4 was $4.35 \%(n=1)$ with one spondyloptosis. All the patients with grades 2 and 4 spondylolisthesis were less than 50 years of life. Whereas $61.90 \%$ of patients with grade 1 spondylolisthesis were above 50 . DS was the commonest type with $52.17 \%(n=12)$. Isthmic type $21.74 \%(n=5)$, traumatic type $8.70 \%(n=2)$ and uncategorised $17.39 \%(n=4) .100 \%$ of all degenerative spondylolisthesis had disc space 
narrowing at the site of listhesis. Anterolisthesis $(91.30 \%, \mathrm{n}=21)$ predominates over retrolisthesis $(8.70 \%, \mathrm{n}=2)$.

Table 2. Vertebral displacements with age range

\begin{tabular}{|c|c|c|c|c|c|c|c|c|c|c|c|}
\hline & $\begin{array}{l}\text { L1 } \\
\text { ON }\end{array}$ & L2 & L2 ON & L3 & L3 ON & L4 & $\begin{array}{l}\text { L4 } \\
\text { ON }\end{array}$ & L5 & $\begin{array}{l}\text { L5 } \\
\text { ON }\end{array}$ & S1 & $\begin{array}{l}\text { T12 } \\
\text { ON }\end{array}$ \\
\hline Age Ran & $\mathbf{M}$ & $F$ & M & $F$ & M & $\mathbf{F}$ & M & $F$ & M & $F$ & M \\
\hline $0-9$ & 0 & 0 & 0 & 0 & 0 & 0 & 0 & 0 & 0 & 0 & 0 \\
\hline $10-19$ & 0 & 0 & 0 & 0 & 0 & 0 & 0 & 0 & 0 & 0 & 0 \\
\hline $20-29$ & 0 & 0 & 0 & 0 & 0 & 0 & 0 & 1 & 0 & 0 & 0 \\
\hline $30-39$ & 1 & 1 & 0 & 0 & 0 & 0 & 0 & 1 & 0 & 2 & 1 \\
\hline $40-49$ & 0 & 0 & 0 & 0 & 1 & 0 & 1 & 1 & 0 & 1 & 0 \\
\hline $50-59$ & 0 & 0 & 0 & 0 & 0 & 0 & 0 & 5 & 1 & 3 & 0 \\
\hline $60-69$ & 0 & 0 & 0 & 0 & 0 & 1 & 0 & 4 & 0 & 0 & 0 \\
\hline $70-79$ & 0 & 0 & 0 & 0 & 0 & 0 & 0 & 0 & 0 & 0 & 0 \\
\hline $80-89$ & 0 & 0 & 0 & 0 & 0 & 0 & 0 & 0 & 0 & 0 & 0 \\
\hline $90-99$ & 0 & 0 & 0 & 0 & 0 & 0 & 0 & 0 & 0 & 0 & 0 \\
\hline Total & 1 & 1 & 0 & 0 & 1 & 1 & 1 & 12 & 1 & 6 & 1 \\
\hline
\end{tabular}

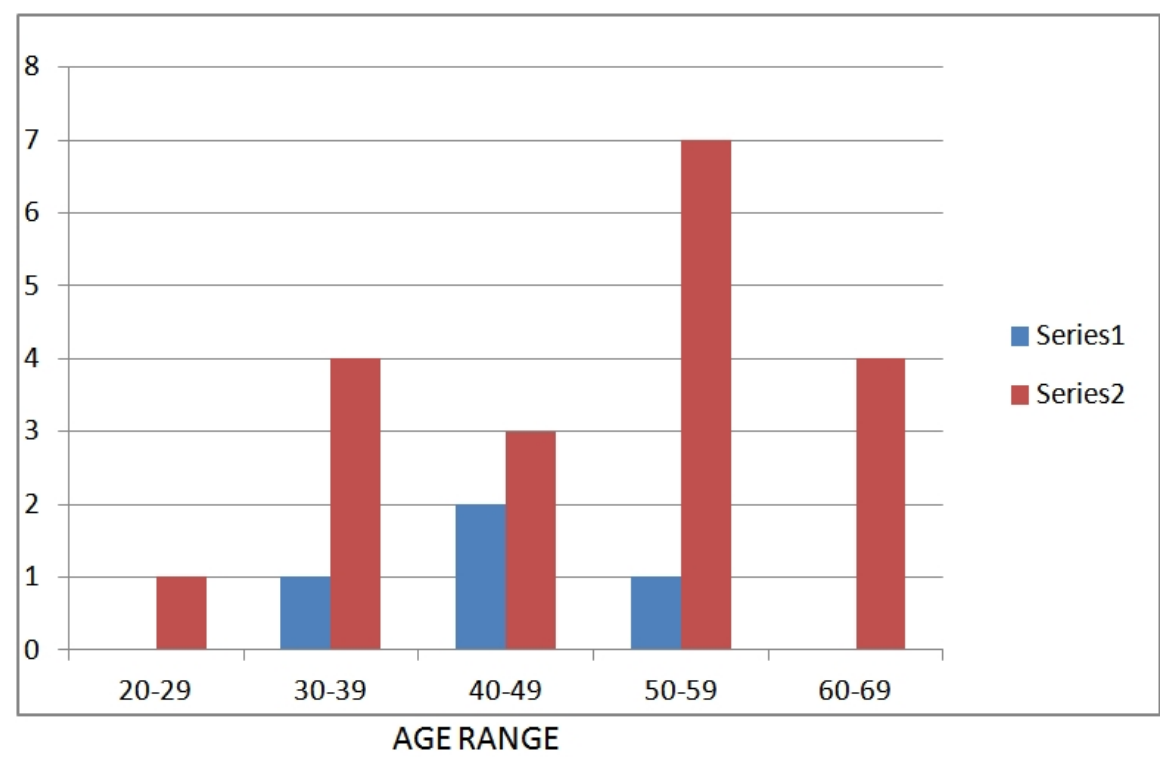

Fig. 1. Sex distribution and age range of spondylolisthesis

Serial 1=Males, Serial 2=Females 


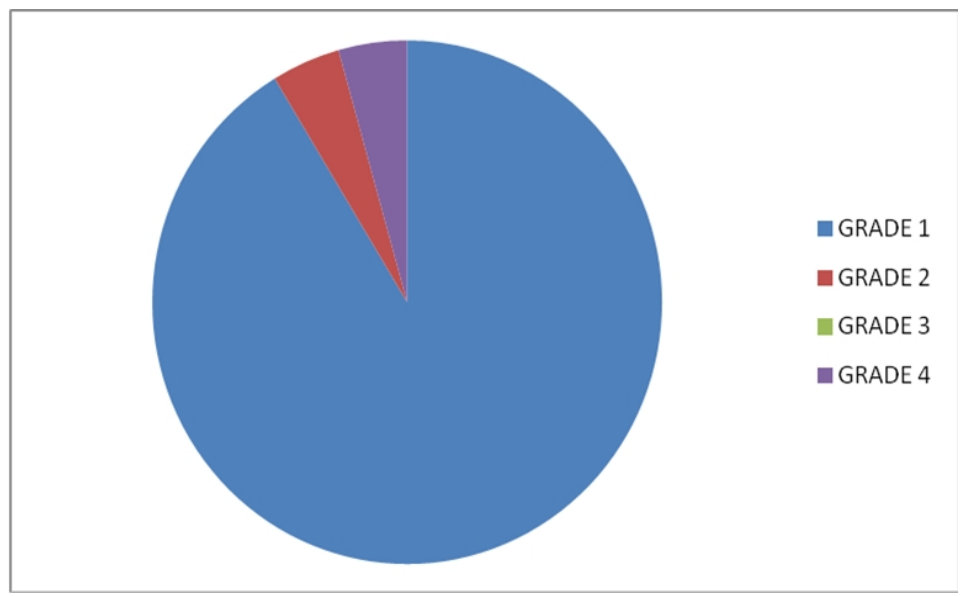

Fig. 2. Grading of spondylolisthesis

\section{DISCUSSION}

Contrariwise to previous studies that observed predominance of isthmic spondylolisthesis, our study showed a predominance of degenerative spondylolisthesis $[1,2,3]$. This may not be unconnected with sample bias, choice of radiological modality and the radiographic views deployed in this study. The sample bias was beyond our control as our study was simply a reflection of who gets referred for x-ray of the lumbo-sacral spine. Also, since the symptomatology essentially revolves on low back pain (LBP), the epidemiology of the studied population naturally skewed towards mid- and older age groups. Studies found out that the incidence of LBP is highest in the third decade, with overall prevalence increasing with age until the 60-65 age group, thereafter gradually declines [17]. In our environ, LBP is treated with levity and dismissed as inconsequential needing no investigations. Investigations become compelling when LBP becomes intractable, persistent or chronic. Therefore, any local study on LBP related entity will invariably means advancing age inclusive study. Little wonder our studied population subsets that were 40 years and above were $78.31 \%$. This will impact on spondylolisthesis evaluations. DS is peculiar to this category of age group unlike isthmic type in young athletics [9]. In fact, it is a disease of the older adult and rarely occurs before the age of 50 years $[3,4,18]$. The correlation to age is a fallout of facet arthritis and facet remodelling [2,3]. As the facets remodel, they take on a more sagital orientation, allowing a mild slip to occur [3]. This facet remodelling in part accounts for the associated narrowing of disc space (seen in $100 \%$ of our cases (See Fig. 4) and central spinal stenosis at the level of the translation in DS unlike wide canal sign in ISS $[3,8,18]$.

Another reason for predominance of DS in this study is due to its asymptomatic nature though it can be associated with symptomatic spinal stenosis $[4,19]$. Correspondingly, these patients will present for radiography at an older age when the spondylolisthesis has now been made symptomatic by an attendant disco-vertebral disease. This will naturally elevates the incidence of DS. Diagnosis of DS is made when in addition to vertebral displacement, other features like osteophytosis, disc space narrowing, end-plate sclerosis are seen [20] (See Figs. 4 and 5). But these features being antecedental or consequential to spondylolisthesis are precarious. Bilateral pars defect is needed to allow slippage in ISS and this is harbingered by trauma and fractures $[1,12]$ (See Fig, 6). Sport specific manoeuvres 
with repetitive twisting, rotation and hyperextension (like gymnasts, football linemen and ballets) increase load on the spine resulting in stress injury and ISS [1,2,4,8,9,12,21]. Most of our patients were relatively beyond the age ceiling for aggressive sports. Therefore the low percentage of ISS in our study is two pronged. Our recruitment was less of young people and our methodology was bereft of bilateral oblique-lateral lumbo-sacral spine radiographic views. On exploit of the later, higher sensistivity is achieved in delineation of spondylolysis, a sine quo non in diagnosis of ISS [2]. Since this was not at our disposal, a few spondylolytic lesions may have been missed, resulting in misclassification of some identified spondylolisthesis [2]. These were regarded as uncategorised in this study as they have neither pars interarticularis defect, degenerative changes, bone pathology nor arose from trauma. Spondylolysis may not always be visible on lateral radiographs [1]. More modern modalities like magnetic resonance imaging (MRI), computed tomography (CT), and single photon emission computed tomography (SPECT) arranged in increasing order of sensitivity in detecting pars articularis defect would have changed our observed trend $[1,9,15]$.

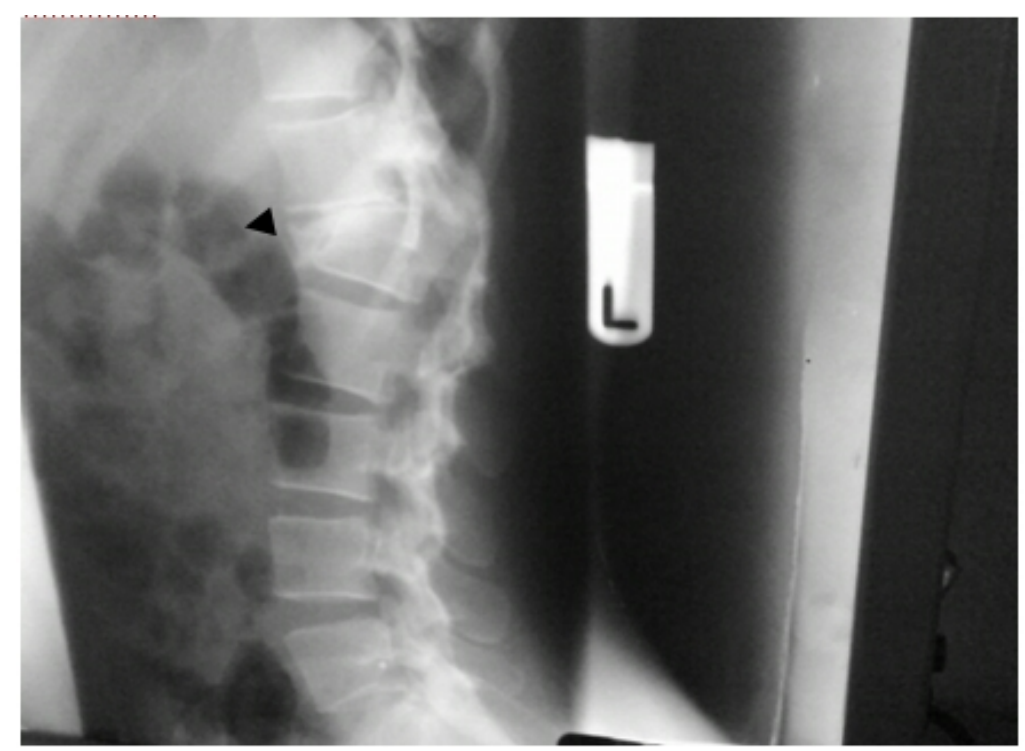

Fig. 3. Lateral lumbo-sacral spine radiograph showing traumatic spondylolisthesis of L1 on L2 with focal lumbar spinal stenosis and anterior wedging of L1 (Source: author) 


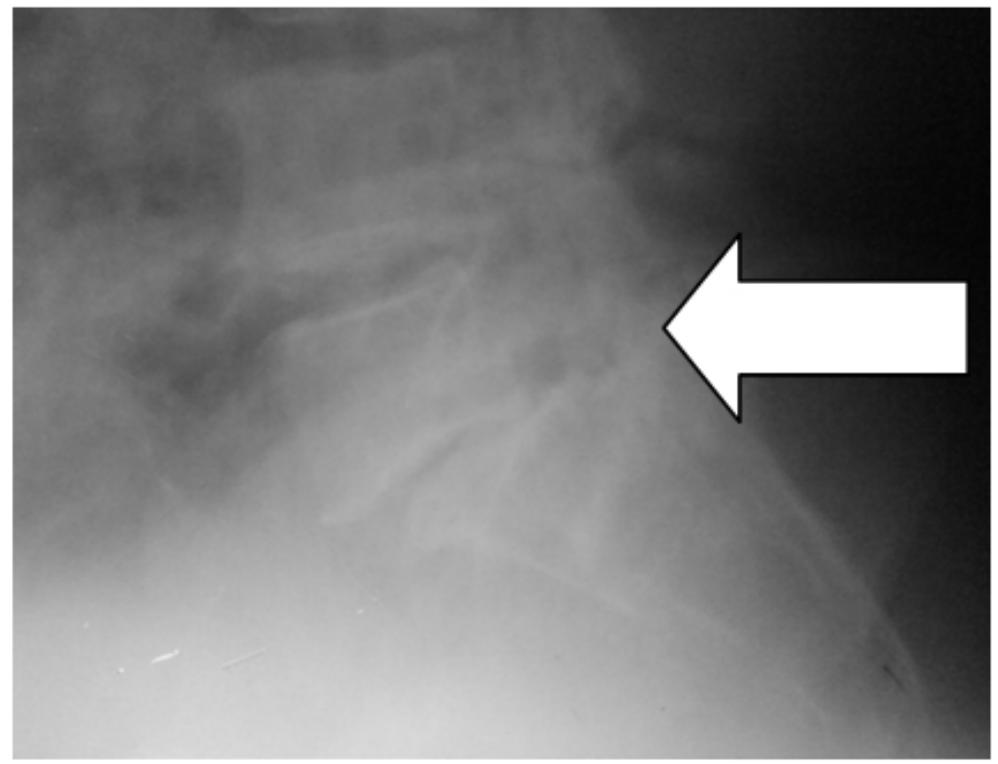

Fig. 4. Lateral lumbo-sacral radiograph showing grade 2 spondylolisthesis with about $30 \%$ slip of L5 on S1 in a degenerative type of spondylolisthesis (Source: author)

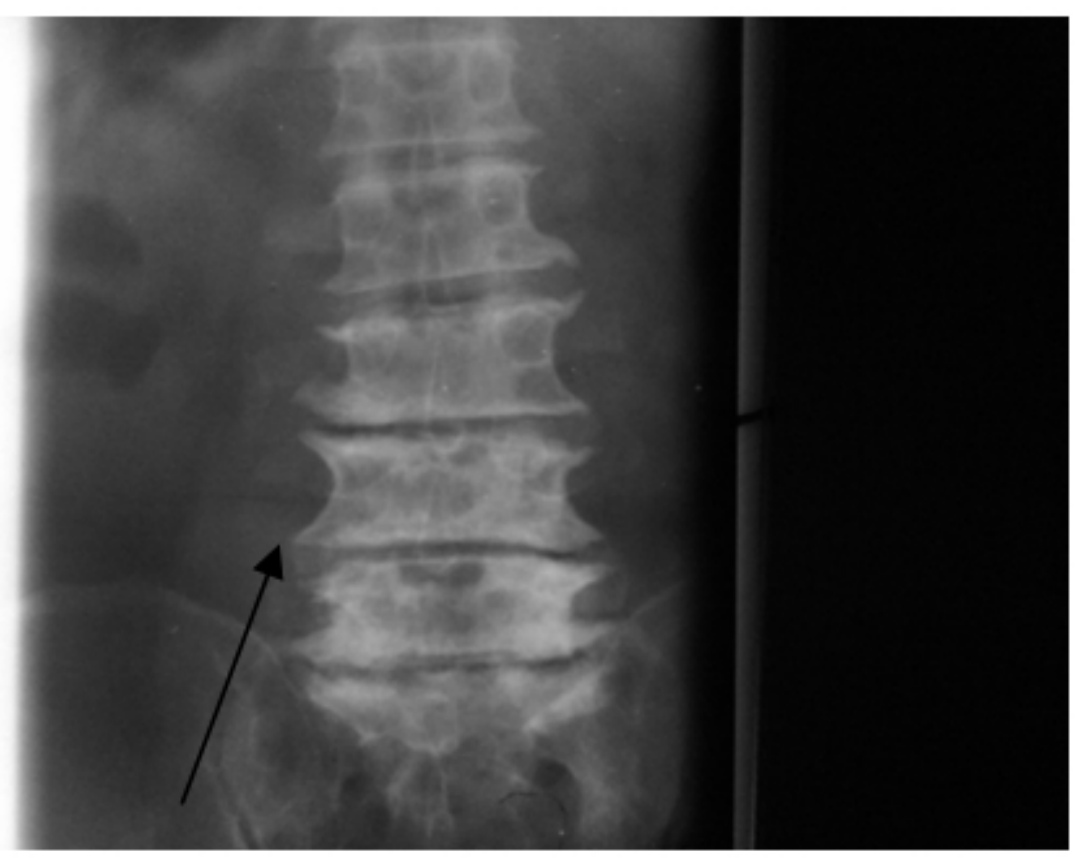

Fig. 5. Anterior-posterior lumbo-sacral spine radiograph showing marginal osteophytosis L2-L5 with narrowed disc spaces seen in degenerative disc diseases

(Source:author) 


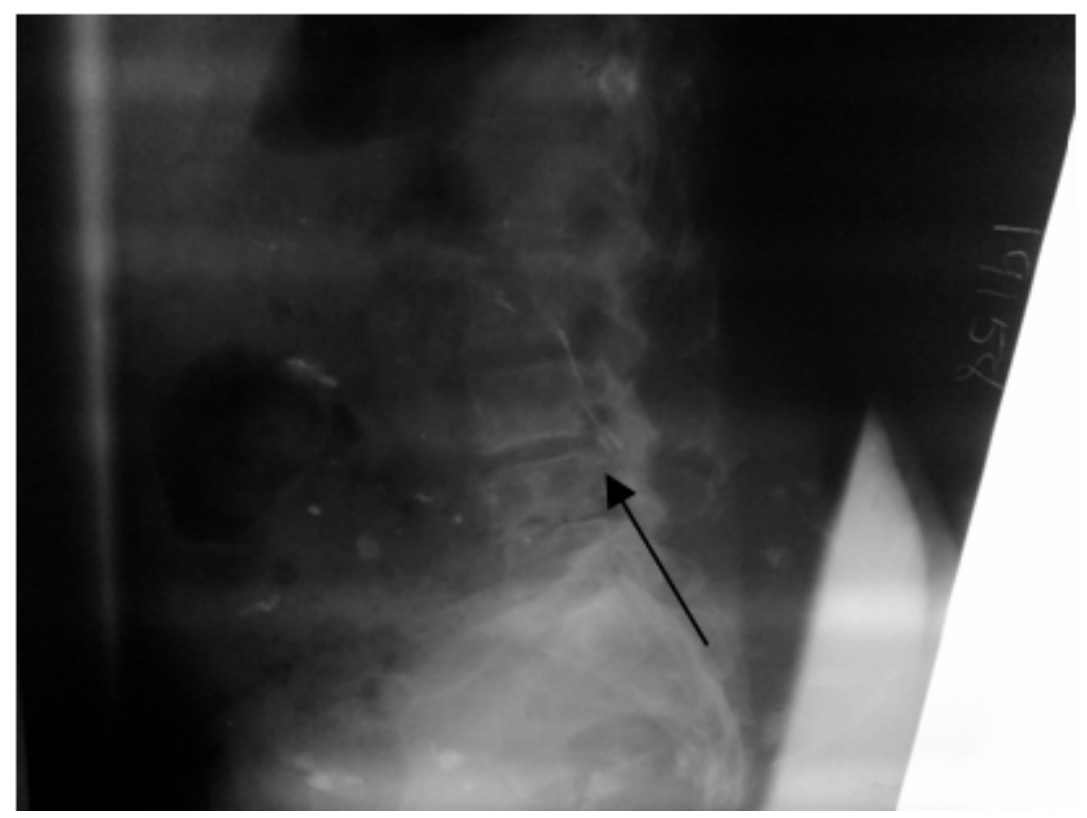

Fig. 6. Lateral lumbosacral radiograph showing stress fracture of L4 pars interarticularis without displacement (Spondylolysis\} a forerunner of isthmic spondylolisthesis. Note narrowed L4/L5 disc space (Source: author)

The entire observed traumatic spondylolisthesis had sinister clinical presentations of paraplegia with horrendous culprit being road traffic accident (RTA) (See Fig. 3) RTA and falls are the commonest causes of bilateral avulsion of the neural arches from the vertebral body with or without subluxation [6]. It is not unusual that dysplastic and pathological spondylolisthesis were not seen in this study as they are rare entities $[3,14]$.

In agreement with other studies, the preferential localization of spondylolisthesis in this study was L4 on L5 followed by L5 on S1 (See Table 2 and Fig. 4) $[4,11,12,15]$. This is linked to vulnerability to micro-trauma from repetitive flexion, extension, rotational forces or increased loading on lower lumbar vertebrae $[8,9]$. Anatomic predisposition also favours this site irrespective of being degenerative or isthmic. Progression of wedge values down the spine, increase in caudal vertebral body height with decrease in posterior elements in the lower lumbar region to create lumbar lordosis encourage spondylolisthesis [22]. Furthermore, the increased incidence of $\mathrm{L} 5$ spondylolisthesis could be due to the complementary role of anterior-posterior lumbo-sacral radiograph. This peculiarly appears as inverted Napoleon Hat sign [23]. Here the anterior border of the transverse process of L5 is in continuity with the anterior border of the body of the same vertebrae in frontal radiograph with projection of anterior border of L5 against the shadow of sacrum [23].

Despite the unintended male bias in our recruitment, in general there is still an overriding incidence of spondylolisthesis among females (See Table 1 and Fig. 1). This female tilt has been noticed in other studies [2.3,4,22]. This disproportionate sex ratio has been unaccounted in the literatures. Future studies on interrelationship of spondylolisthesis and sex hormone profiles will therefore be exciting. 
Grade 1 spondylolisthesis predominates just like in other studies [3,4] (See Fig. 2). It is noteworthy that all our patients with grades 2 and 4 spondylolisthesis were less than 50 years of age whereas $61.90 \%$ of grade 1 spondylolisthesis were above 50 . This implies that more forceful impact readily associated with youthfulness is needed in the aetiogenesis of high grade spondylolisthesis. High-grade slips are much rarer, less than $10 \%$ of spondylolisthesis, and majority present during adolescence $[3,24]$. This is comparable to our $4.35 \%$ and younger are group.

The treatment of spondylolisthesis is conservative but surgery is contemplated in the presence of treatment unresponsiveness $[6,25]$. Conservative treatment consists of activity modification, pharmacological intervention and physiotherapy $[3,26]$. The surgical goals are neural decompression and solid bony fusion [25].

The limitation of this study is the non-utilization of bilateral oblique-lateral views. This may probably increase the incidence of isthmic spondylolisthesis in our environ but our patients were not just ready to tolerate further receipt of radiation dose. Nevertheless, we think this drawback does not understate our findings as lateral radiograph still serves as alternative in detecting spondylolysis, hallmark of isthmic spondylolisthesis.

\section{CONCLUSIONS}

There is a disproportionate female gender bias in spondylolisthesis in Uyo, Nigeria. While the typical predominance of grade 1 and slippage localisation of L4 on L5 are obeyed, contrariwise, degenerative spondylolisthesis predominates over the usual isthmic type.

\section{CONSENT}

All authors declare that 'written informed consent was obtained from the patient (or other approved parties) for publication of this article and accompanying images.

\section{ETHICAL APPROVAL}

All authors hereby declare that all experiments have been examined and approved by the appropriate ethics committee and have therefore been performed in accordance with the ethical standards laid down in the 1964 Declaration of Helsinki.

\section{ACKNOWLEDGEMENTS}

Staff of Radiology Department, UUTH, Uyo, Nigeria.

\section{COMPETING INTERESTS}

The authors declare that they have no competing interests.

\section{REFERENCES}

1. Irani Z. Spondylolisthesis- imaging. E-Medicine; 2011. Accessed $14^{\text {th }}$ May; 2011. Available: http://emedicine.medscape.com/article/396016-overview. 
2. Chain JC, Chan WP, Katz JN, Chang WP, Christam DC. Occupational and personal factors associated with acquired lumbar spondylolisthesis of urban taxi driver. Occup Environ Med. 2004;61:992-998. doi:10.1136/oem.2003.011775.

3. Wikipedia, Spondylolisthesis. 2008. Accessed $4^{\text {th }}$ July; 2012. Available: http://en.wikipedia.org/wiki/Spondylothesis. 2008.

4. Eck JC. Spondylolisthesis. Medicinet. 2012. Accessed $3^{\text {rd }}$ May, 2012. Available: http://www.medicinenet.com/spondylolisthesis/article.htm.

5. Li Y, Hresko MT. Radiographic analysis of spondylolisthesis and sagital spinopelvic deformity. J Am Acad Orthop. 2012;20(4):194-205.

6. Sirkis HM. Traumatic spondylolisthesis of the axis (hangman's fracture), type 1. Applied Radiology. 2005;34(8).

7. Niggermann P, Kuchta J, Grosskurth D, Beyer HK, Hoeffer J, Delank KS. Spondylolysis and isthmic spondylolisthesis: Impact of vertebral hypoplasia on the use of Meyerding classifications. BJR. 2012;85:358-362. doi: 10.1259/bjr/60355971.

8. Toueg CW, Mac-Thiong JM, Grimard G, Parent, S, Poitras B, Labelle H. Prevalence of Spondylolisthesis in a Population of Gymnasts. Studies in Health Technology and Informatics. 2010;158.

9. Zukotynski K, Curtis C, Grant FD, Micheli L, Treves ST. The value of SPECT in the detection of stress injury to the pars interarticularis in patients with low back pain Journal of Orthop. Surg. and Research. 2010;5:13. doi:10.1186/1749-799X-5-13.

10. Ulmer JL, Mathew VP, Elster AD, Mark LP, Daniel DL, Mueller W. MRI imaging of lumbar spondylolysis: The importance of ancillary observations. Am J of Roentgenolo, 1997;169(1):233-239.

11. Aono K, Kobayashi T, Jimbo S, Atsuta Y, Matsuno T. Radiographic analysis of newly developed degenerative spondylolisthesis in a mean twelve-year prospective study. Spine. 2010;35(8):887-91.

12. Bock C, Stock K. L5 Spondylolysis with Grade I L5/S1 Spondylolisthesis (Meyerding Classification) Ped Rad. 2004;4(1). Accessed 23 June 2011. Available: www.PedRad.info/?search $=20040113153041$.

13. Kirkman MA, Sridhar K. Posterior listhesis of a lumbar vertebra in spinal tuberculosis. Euro Spine J. 2011;20(1):1-5. DOI: 10.1007/s00586-010-1524-5.

14. Chadha M, Agarwal A, Kumar S. Spinal tuberculosis with concomitant spondylolisthesis: coexisting entities or 'cause and effect'? Spinal Cord. 2006;44(6):399-404.

15. Huang $\mathrm{K}$, Lin R, Lee $\mathrm{Y}$, Li J. Factors affecting disability and physical function in degenerative lumbar spondylolisthesis of L4-5: evaluation with axially loaded MRI. Eur Spine J. 2009;18(12):1851-1857. doi: 10.1007/s00586-009-1059-9.

16. Stanislavky A, Gaillard F. Spondylolisthesis grading system. Radiopaedia; 2005. Accessed 24 $4^{\text {th }} \quad$ August, $2012 . \quad$ Available: http://radiopaedia.org/articles/spondylolisthesis-grading-system.

17. Hoy D, Brooks P, Blyth F, Buchbinder R, Baillieres R. The Epidemiology of low back pain. Best Pract Res Clin Rheumatol. 2010;24(6):769-81.

18. Ulmer JL, Elster AD, Mathews VP, King JC. Distinction between degenerative and isthmic spondylolisthesis on sagittal MR images: importance of increased anteroposterior diameter of the spinal canal ("wide canal sign"). AJR. 1994;163(2):411-416.

19. Niggemann P, Kuchta J, Beyer H, Grosskurth D, Schulze T, Delank K. Spondylolysis and Spondylolisthesis: Prevalence of Different Forms of Instability and Clinical Implications. Spine. 10.1097/BRS.0b013e3181d47a0e 
20. Pye SR, Reid DM, Lunt M, Adams JE, Silman AJ, O'Neill TW. Lumbar disc degeneration: association between osteophytes, end-plate sclerosis and disc space narrowing. Ann Rheum Dis. 2007;66:330-333.

21. Yoong-Leong Oh J, Liang S, Louange D, Rahmat R, Hee H, Kumar VP. Paradoxical motion in L5-S1 adult spondylolytic spondylolisthesis. Euro Spine J. 2012;21(2):262267. DOI: 10.1007/s00586-011-1880-9.

22. Wilms G, Maidague B, Parizel P, Meylaerts K, Vannesta D, Pelusol J. Hypoplasia of L5 and Wedging and Pseudospondylolisthesis in Patients with Spondylolysis: Study with MR Imaging. AJNR. 2009;30:674-680.

doi: 10.3174/ajnr.A1450.

23. Gentili A, Beller M, Masih S, Seeger L. Atlas of Signs in Musculoskeletal Radiology is approved by the American Roentgen Ray Society. 2000. Accessed $23^{\text {rd }}$ August, 2011. Available: http://www.gentili.net/signs/14.HTM.

24. Denard PJ, Holton K F, Miller J., Fink H A, Kado D M, Marshall L M, Yoo J U. Osteoporotic Fractures in Men Study Group. Back pain, neurogenic symptoms, and physical function in relation to spondylolisthesis among elderly men. The Spine Journal. 2010;10(10):865-873.

25. Tender GC, Miller LE, Block JE. Percutaneous pedicle screw reduction and axial presacral lumbar interbody fusion for treatment of lumbosacral spondylolisthesis: A case series. Journal of Medical Case Reports. 2011;5:454. doi:10.1186/1752-1947-5454.

26. Weinstein JN, Lune JD, Tosteson TD, Hanscom B, Tosteson ANA, Blood EA, et al. Surgical versus Nonsurgical Treatment for Lumbar Degenerative Spondylolisthesis. $\mathrm{N}$ Engl J Med. 2007;356:2257-2270.

(c) 2013 Felix et al.; This is an Open Access article distributed under the terms of the Creative Commons Attribution License (http://creativecommons.org/licenses/by/3.0), which permits unrestricted use, distribution, and reproduction in any medium, provided the original work is properly cited.

\section{Peer-review history:}

The peer review history for this paper can be accessed here: http://www.sciencedomain.org/review-history.php?iid=194\&id=12\&aid=1011 